\title{
Isometric Peak Force of Shoulder Rotators in Cricketers with and without History of Shoulder Pain
}

\author{
Juneja, $\mathbf{H}^{1}$, Verma ${ }^{2}$, S.K., Khanna ${ }^{3}$, G.L. \\ ${ }^{1} \mathrm{Ph} . \mathrm{D}$ student, Department of Sports Sciences, Punjabi University, Patiala. India email: \\ hemantjuneja@ rediffmail.com \\ ${ }^{2}$ Professor, Department of Sports Sciences, Punjabi University, Patiala. India e mail: satishsk1@ rediffmail.com \\ ${ }^{3}$ Dean, Faculty of Allied Health Sciences, Manav Rachna International University, Faridabad, Haryana, India \\ email : glkhanna@gmail.com
}

\section{Abstract}

Aim: To find out the differences in Shoulder External and Internal Rotator strength and their ratios in cricketers with and without history of shoulder pain.

Background: Throwing activity imposes specific demands on shoulder muscles leading to imbalances especially between the External rotators (ER) and Internal rotators (IR). This study aims to investigate the isometric strength differences of shoulder ER and IR in cricketers with and without history of pain.

Materials \& Methods: 52 healthy subjects between the age group of 16-18 with a mean age of $16.97 \pm 0.55$ years were recruited for this study. The subjects were divided into two groups a) those with history of pain $(\mathrm{PH})$ which restricted throwing within the past 2 years- Group 1 and b) no history of pain (NPH)-Group 2. Isometric Shoulder External Rotator (ER) and Internal rotator (IR) maximal force was measured and Isometric ER: IR ratios were calculated.

Results: Significant differences were found in the isometric strength of ER and consequently ER:IR ratios between the two groups. However, no differences were found in the IR force between the two groups. PH group showed a mean ER force (in $\mathrm{kg}$ ) of $7.38 \pm .71(\mathrm{SD})$ while the mean ER force in NPH Group was $9.90 \pm 1.32$ (SD). ER: IR force ratios were found to be 0.60 \pm .045 in the PH group while in the NPH group it was $0.82 \pm .049$.

Conclusion: The results of our study suggest that Isometric strength differences in shoulder rotators exist between sportspersons with and without history of shoulder pain. In addition to the advanced techniques of muscle force evaluation such as isokinetics, isometric measurements can also play an important role in evaluating muscle force.

Key words: External Rotators, Internal Rotators, Isometric, Isokinetic, Throwing

\section{Introduction}

Shoulder injuries in sports involving throwing actions are extremely common and often result in prolonged periods of absence from sporting activities (Aagaard \& Jorgensen, 1996; Wang \& Cochrane, 2001; Kettunen et al, 2011). The glenohumeral joint is inherently unstable due to its bony configuration and the degrees of freedom of movement.
Therefore, it is dependent to a great extent on the ligaments and muscular structures to provide stability. High speed throwing actions requires frequent and synchronized activation of these stabilization mechanisms, specially the shoulder rotator muscles (Bayios et al, 2001; Yildiz et al, 2006). During the acceleration phase of throwing, the supraspinatus, infraspinatus and teres minor work eccentrically to provide 
stability to the humeral head and prevent excessive anterior translation of the humeral head. This predisposes the sportspersons to painful syndromes of the shoulder rotator muscles in a variety of sports involving aggressive throwing. Therefore, an objective evaluation of shoulder rotator strength is crucial for rehabilitation and prevention of shoulder injuries.

Extensive work has been done by various authors on measurement of External and Internal rotator strength in different types of sports persons (Aldenrink \& Kuck, 1986; Chandler et al, 1992; McMaster et al, 1992). In addition to Isokinetic shoulder External rotator(ER) and Internal Rotator (IR) strength, Isokinetic strength ratios have been used by various authors to predict and study performance, stability, injury patterns and strength differences between dominant and non dominant upper extremity (Aldenrink \& Kuck, 1986; Chandler et al, 1992; McMaster et al, 1992; Stickley et al, 2008). Lot of differences exists in the testing methodologies of rotator muscles strength with regards to the position of the shoulder, test speeds and modes of contraction in these studies (Nadine et al, 2002). Majority of work done on shoulder strength in overhead athletes has been done using Isokinetic type of muscle work in the concentric and eccentric mode clearly due to the reason that a Isokinetic measurements allows high reproducibility $(\mathrm{r}=0.82-0.96)$ (Pincivero et al, 1997) and measurements at high speeds with accommodating resistance which was thought of as having more relevance to function.

Although Isokinteuc testing in sports is a preferred mode of testing, it is interesting to note that the maximal velocity allowed by Isokinetic apparatus reaches only $40 \%$ of the maximal velocity that can developed by leg extensor muscles during ballistic motion (Bosco et $a l, 1982 b$ ) and only $10 \%$ of the maximal velocity obtained by shoulder during throwing motion (Pappas et al, 1985). Also, Isokinetic testing does not always predict the performance differences between athletes possessing different skill levels (Fry et al, 1991; Hurley et al, 1988). In spite of the potential clinical relevance of measurement of isometric strength, there appears to be considerable controversy regarding the use of isometric assessment and the ability of these tests to monitor changes in dynamic performance. Isokinetic strength was found to be related to Isometric measurements in a study by Lord et al (1992). In a recent study Folland et al., reported that after Isometric training at 4 angles in one leg and Isokinetic in the other leg of same subjects, 9 weeks later the Isokinetic gains were similar in both legs ${ }^{18}$. Furthermore, isometric measurements using hand dynamometers and strain gauge have a high test -retest reliability in comparison to manual muscle testing and are reported to be comparable to Isokinetic testing in some studies (Magnusson et al, 1990; Kuhlman et al, 1992; Malerba et al, 1993). Therefore, the literature does indicate that isometric testing in sports has the potential to analyze effects of injury and guide the rehabilitation process.

Isokinetic strength ratios of shoulder rotators in symptomatic and non symptomatic sportspersons have been studied previously by various authors. Significant differences in the rotator cuff muscles and scapular muscles primarily 
through Isokinetic measurements have been reported as a result of shoulder pain and injuries (MacDermid et al, 2004; McCabe et al, 2005; Tyler et al, 2005) but there is hardly any literature reporting Isometric strength changes in glenohumeral rotators in such population. Therefore, we hypothesize that there will a difference in Isometric strength of External and Internal rotators of shoulders and their ratios in cricketers with and without history of shoulder pain.

\section{Materials and Methods}

The subjects were volunteers from cricket training academies and were playing cricket for at least 5 years. Fifty two (52) subjects were recruited for the study. These 52 participants were currently pain free but out of these, 14 participants reported a previous history of shoulder pain once or more in the past 2 years which interrupted their throwing activities for few days. These 14 subjects were categorized as Group I (PH -Pain history) and the remaining 38 were categorized as Group 2(NPH-no pain history) for study purposes. Their mean age, height and weight are mentioned in Table 1 . Only 2 participants were left handed.

Table 1: Means of Physical characteristics of two groups

\begin{tabular}{llll}
\hline $\begin{array}{l}\text { No. of } \\
\text { subjects }\end{array}$ & $\begin{array}{c}\text { Age (in } \\
\text { years) } \pm \text { SD }\end{array}$ & $\begin{array}{l}\text { Height (in } \\
\text { cms) } \pm \text { SD }\end{array}$ & $\begin{array}{l}\text { Weight(in } \\
\text { kg) } \pm \text { SD }\end{array}$ \\
\hline $\begin{array}{l}\text { Group I } \\
\text { (PH) }\end{array}$ & $16.78 \pm 0.38$ & $167.4 \pm 3.1$ & $65.54 \pm 4.90$ \\
$\begin{array}{l}\text { Group } 2 \\
\text { (NPH) }\end{array}$ & $17.04 \pm .59$ & $168.6 \pm 3.8$ & $66.07 \pm 5.67$ \\
Total & $16.97 \pm .55$ & $168.3 \pm 3.6$ & $65.93 \pm 5.43$ \\
\hline
\end{tabular}

Isometric Force measurements

All the 52 subjects completed a standard warm up protocol consisting of
10 overhead movements through complete range of abduction, 5 stretches of 6 seconds hold for internal rotators by performing horizontal abduction till comfortable stretch is felt and 5 stretches of 6 seconds hold for the external rotators by touching the opposite scapula till a comfortable stretch is felt .

\section{Instrumentation}

Isometric strength measurements of Shoulder rotators of dominant upper limb were obtained using a digital strain gauge with a range of 0 $120 \mathrm{~kg}$ with sensitivity of $.01 \mathrm{~kg}$. Although there are sophisticated, computerized isometric dynamometers available nowadays, the portable hand held strain gauge has greater flexibility and may be carried by the therapist to evaluate patients in different settings. Isometric testing using strain gauge has been proved to have high inter-rater and intra- rater reliability (Bohannon \& Andrews, 1987).

\section{Isometric External Rotator (ER) force}

The measurements were done in supine position with elbow just on the edge of measuring surface and the forearm out of the couch for measurements. The shoulder External Rotator(ER) strength was measured with the subjects arm and forearm in a position close to that of throwing position which is $90^{\circ}$ of abduction and $90^{\circ}$ degrees of external rotation (Sapega et al, 1982). Strain gauge which was attached perpendicularly to subject's forearm with the help of a wrist strap placed just proximal to the styloid process (Andrews et al, 1996). The stationary end of the strain gauge was attached to a specially designed frame with the help of adjustable chains and screw mechanisms suspended 
from the top. The arm component was stabilized using straps and elbow flexion was maintained at $90^{\circ}$ throughout the measurements. Following warm-up procedures, each subject was asked to force into external rotation as "hard and fast" as it produces optimal results for recording maximal force (Bemben et al, 1990; Sahaly et al, 2001; Haff et al, 2005).

\section{Isometric Internal Rotator (IR) Force}

The Isometric Internal Rotator force were measured using a similar method as that for External rotator but in prone position so that the subjects could force into Internal rotation while the arm was abducted and externally rotated to $90^{\circ}$ and the elbow was flexed to $90^{\circ}$. Both the groups were instructed to stop forcing in case of any pain. The authors felt that Group 1(PH) had higher chances of developing pain during the process. Although none of the subjects reported pain during the measurement process, some subjects in Group 1 informed that they felt reduced force capacity during forcing into external rotation in supine. The Isometric ER: IR ratios were calculated using the ER and IR Isometric force.

\section{Data Analysis}

The data was analyzed using SPSS 16.0. Independent samples t-test was performed to compare the means of (a) Isometric External rotators(ER) force (b) Isometric Internal Rotator(IR) Force (c) Ratio of ER:IR between PH(1) and NPH(2) groups. The $\alpha$ level was set at .05

\section{Results}

The means of isometric shoulder rotator force is shown in Table 2. The
Isometric force of External rotators showed a significant difference between the two groups (Fig 1). Group $1(\mathrm{PH})$ showed a mean force (in $\mathrm{kg}$ ) of $7.38 \pm$ .71(SD) while the mean ER force in Group 2(NPH) was $9.90 \pm 1.32(\mathrm{SD})$. $\mathrm{p}<.000$

The Internal Rotator muscle force in Group $1(\mathrm{PH})$ had a mean of $12.27 \pm .96$ and in Group $2(\mathrm{NPH})$ it was $12.10 \pm 1.38$. No significant differences were found between the two groups (Fig 2) $(\mathrm{p}=0$.618).

As is evident from the results of ER and IR Isometric forces, the ratios of External rotators force to internal rotator force showed significant differences between two groups. The mean ER: IR force ratios in Group $\mathrm{I}(\mathrm{PH})$ were $0.60 \pm$ 0.045 and in Group 2(NPH) was $0.82 \pm$ 0.05 (Fig 3).

Table 2: Means of Isometric ER, IR forces \& ER: IR ratios

\begin{tabular}{|c|c|c|c|}
\hline & $\begin{array}{l}\text { External } \\
\text { Rotators } \\
\text { force (in kg) } \\
+ \text { SD }\end{array}$ & $\begin{array}{l}\text { Internal } \\
\text { Rotator } \\
\text { Force(in } \\
\text { kg) +SD }\end{array}$ & $\begin{array}{l}\mathrm{ER} / \mathrm{IR} \\
\text { ratios in } \\
\mathrm{kg}+\mathrm{SD}\end{array}$ \\
\hline $\begin{array}{l}\text { Group I } \\
\text { (PH) }\end{array}$ & $7.38 \pm .71$ & $12.27 \pm .96$ & $.60 \pm .045$ \\
\hline $\begin{array}{l}\text { Group } 2 \\
\text { (NPH) }\end{array}$ & $9.90 \pm 1.32$ & $\begin{array}{l}12.10 \pm \\
1.38\end{array}$ & $.82 \pm .049$ \\
\hline $\begin{array}{l}\text { Group } 1 \text { vs } \\
\text { Group } 2\end{array}$ & $P<.000$ & $P=.618$ & $P<.000$ \\
\hline
\end{tabular}

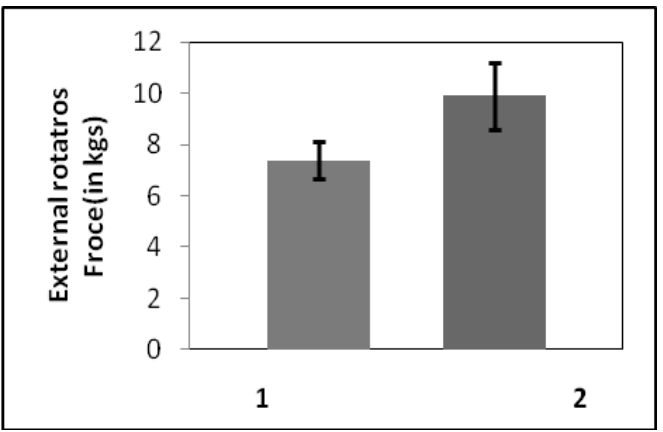

Figure 1: Mean of Isometric External rotator(ER) Force in two groups $(p<.000)$ 


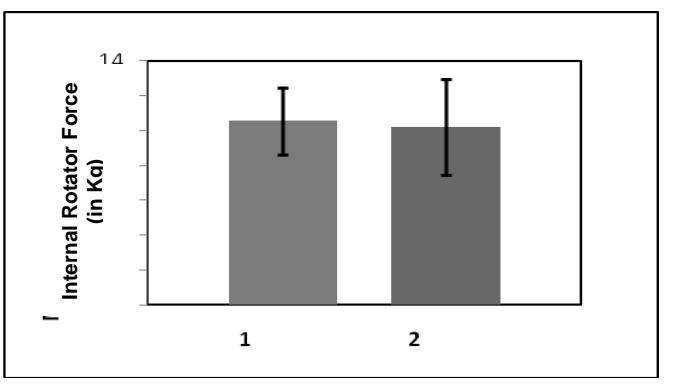

Figure 2: Means of Isometric Internal Rotator (IR) force in two groups $(p=.618)$

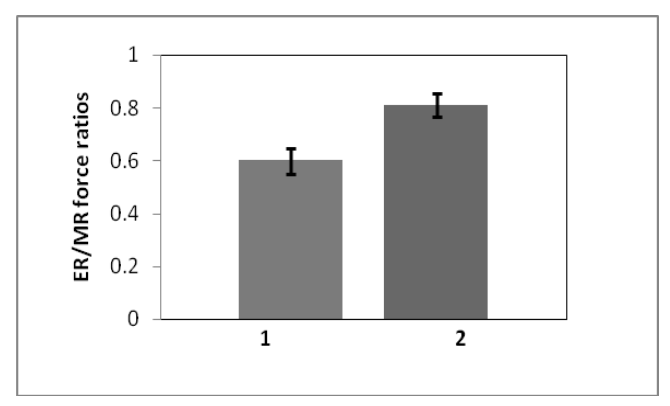

Figure 3: Means of Isometric ER: IR force ratios of two groups $(p<.000)$

\section{Discussion}

In spite of the potential clinical relevance of isometric strength measurements, there appears to be considerable controversy regarding the use of isometric muscle force evaluation and the ability of these tests to monitor changes in dynamic performance and predicting injuries. Although some studies have reported that isometric strength may not be related to function (Murphy \& Wilson, 1996), there is evidence to support the relationship of Isokinetic and Isometric measurements (Lord et al, 1992; Folland et al, 2005). This is interesting to note since Isokinetic evaluation and training has been used by various authors to study muscle performance in sportspersons as muscle work at various speeds could be evaluated using this technique. However, it has also been reported that the speeds of testing and training in Isokinetic muscle testing are much lesser than actual speeds of sporting activities such as throwing and jumping (Bosco et al, 1982b; Pappas et al, 1985). Isometric strain gauge measurements have been reported to be reliable (Bohannon \& Andrews, 1987) and can objectively quantify the muscle force or strength also. However their relationship to dynamic activities has been questioned by various authors.

Injuries and dysfunction of the shoulder in throwing can be attributed to a multitude of factors, including anatomical, biomechanical, and environmental concerns. The Internal rotator (IR) and External rotator (ER) muscles of the shoulder play a critical role in providing stability and mobility to the glenohumeral joint, particularly in overhead athletes (Ramsl et al, 2004). Several authors have investigated muscular imbalance of the shoulder rotators using Isokinetic devices to identify any imbalancs in normal sportsperson involved in throwing (Aldenrink \& Kuck, 1986; Chandler et al, 1992; McMaster et al, 1992) and reported ratios of Eccentric ER: Conc IR and Conc ER: Conc IR. But Isometric ratios of these muscles were not evaluated in these studies. In the present study we utilized Isometric tests to assess the muscular strength of shoulder rotators in subjects with and without history of pain.

Internal Rotator (IR) Isometric force in all 52 subjects was more than the External rotator (ER) Isometric force. Although a direct comparison cannot be made with other studies involving Isokinetic ER: IR strength ratios, our results do have some similarity in the patterns reported in these Isokinetic studies which have shown ER strength to be lesser than IR strength in throwers but not at high speeds (Cook et al, 1987; 
Hinton, 1988; Ellenbecker \& Mattalino, 1997; Guillermo \& Noffal, 2003). Most studies on normal athletes involved in throwing activities have shown that due to demands imposed on the internal rotators, they tend to become stronger than the External rotators with time. The Isokinetic measurements in previous studies ( $C$ Cook et al, 1987; Hinton, 1988; Guillermo \& Noffal, 2003) have shown an ER (conc.): $\mathrm{IR}$ (conc) of 0.65 to 0.71 . The maximal isometric force in subjects without any history of pain (NPH) showed ER: IR ratios of 0.82 at 90 degree of external rotation. However, the Isometric ER: an IR ratio in the $(\mathrm{PH})$ group was found to be 0.60 which was significantly lower than that of non painful group. Isokinetic ER: IR findings of Stickly et al (2008) also reported lower ratios in adolescent volleyball players with injury history.

Although, the number of subjects in the PH group was not high in our study, it is definitely possible that the causative factors of pain were different in different subjects. Further research is definitely warranted to investigate whether external rotator force can be affected by different types of shoulder problems. Furthermore, the results of our study and also those of many other previous studies do not establish a cause effect relationship between the strength ratios and incidence of shoulder pain or injury. There is a probability that the subjects developed painful shoulders as a result of this muscle imbalance or the imbalance was a result of the injury. A long term follow up of throwers with ER: IR imbalances are required to answer this question.

Another key area which can be focused in future researches is the correlation between the Isometric and Isokinetic ratios to find out the relationship between them. According to Folland et al (2005) isometric strengthening at multiple angles led to gains in Isokinetic strength. This is a crucial finding in view of the controversies surrounding the Isometric measurement and its relationship to dynamic performance. In our study, the results clearly highlight the fact that throwers with history of pain in dominant shoulders had significant Isometric strength deficits in their external rotator force when compared to their normal counterparts.

An interesting finding was that although all our subjects were professional cricketers and were training regularly with therabands and other resistive devices, the ER strength deficits still persisted. In our opinion, this was the result of lack of objective measurements of shoulder strength and a systematic progressive resisted program targeted towards improving imbalance between the two groups of muscles. Therefore, it is essential that after injuries and painful overuse syndromes of the shoulder in sportspersons, objective measures are utilized to analyze and correct the muscle imbalance of shoulder rotator muscles.

\section{Conclusion}

The results of our study indicate that Isometric strength and strength ratios of shoulder rotators can provide useful information in sportspersons with history of injury or pain in the shoulder. Isometric strength imbalances between the ER and IR may also guide the treating professional in correcting these discrepancies using objective methods. Our study also highlights the facts that in addition to the advanced techniques of muscle force evaluation such as 
Isokinetics. Isometric force measurements can also play an important role in evaluating muscle force and that their role cannot be completely ignored.

\section{References}

Aagaard, H., Jorgensen, U. 1996. Injuries in elite volleyball. Scand. J. Med. Sci. Sports. 6(4): 228-232.

Aldenrink, G.J., Kuck, D.J. 1986. Isokinetic shoulder strength of high school and collegeaged pitchers. J. Orthop. Sports Phys. Ther, 7: 163-172.

Andrews, A.W., Thomas, M.W., Bohannon, R.W. 1996. Normative Values for Isometric Muscle Force Measurements Obtained With Hand-held Dynamometers. Phys. Therap. 76(3): 248-259.

Bayios, I.A., Anastasopoulou, E.M., Sioudris, D. \& Boudolos, K. D. 2001. Relationship between Isokinetic strength of the internal and external shoulder rotators and ball speed in team handball. J. Sports Med. Phys. Fit. 41: $229-235$

Bemben, M.G., Clasey, J.L. Massey, B.H. 1990. The effect of the rate of contraction on the force-time curve parameters of male and female subjects. Res. Quart. 61(1): 96-99.

Bohannon, R.W., Andrews, A.W. 1987. Inter-rater reliability of hand held dynamometry. Phys. Therap. 67(7): 931-33

Bosco, C., Ito, A., Komi, P.V. et al. 1982b. Neuromuscular function and mechanical efficiency of human leg extensor muscles during jumping exercises. Acta. Physiol. Scand. 114(4): 543-50.

Brussock, C.M., Haley, S.M., Munsat, T.L., Bernhardt, D.B. 1992. Measurement of isometric force in children with and without Duchenne's muscular dystrophy. Phys. Ther. 72(2):105-14.

Chandler, T.J., Kibler, W.B., Stracener, E.C., et al 1992. Shoulder strength, power, and endurance in college tennis players. Am. J. Sports Med., 20: 455-458

Cook E.E., Gray, V.L., Savinar-Nogue, E., et al 1987. Shoulder antagonistic strength ratios: A comparison between college-level baseball pitchers and nonpitchers. J Orth. Sports Phys. Ther., 8: 451-461.

Ellenbecker, T.S., Mattalino, A.J. 1997. Concentric Isokinetic shoulder internal and external rotation strength in professional baseball pitchers. J. Orth. Sports Phys. Ther., 25: 323-328,

Folland, J.P., Hawker, K., Leach, B., Little, T., \& Jones, D.A. 2005. Strength training: Isometric training at a range of joint angles versus dynamic training. J. Sports Scien. 23(8): 817 - 824 .

Fry, A.C., Kraemer, W.J., Weseman, C.A., et. al 1991. Effects of an off-season strength and conditioning program on starters and nonstarters in women's collegiate volleyball. J. Appl. Sport Sci. Res. 5: 174-81.

Guillermo, J. N. 2003. Isokinetic Eccentric-toConcentric Strength Ratios of the Shoulder Rotator Muscles in Throwers and Nonthrowers. Am. J. Sports Med. 31(4): 537541

Haff, G.G., Carlock, J.M., Hartman, M.J, Kilgore, J.L., Kawamori, N., Jackson, J.R., Morris, R.T., Sands, W.A., and Stone, M.H. 2005. Force-time curve characteristics of dynamic and isometric muscle actions of elite women Olympic weightlifters. J. Stren. Cond. Res. 19: $741-748$.

Hinton, R.Y. 1988. Isokinetic evaluation of shoulder rotational strength in high school baseball pitchers. Am. J. Sports Med. 16: 274-279.

Hurley, J.M., Hagberg, J.M., Holloszy, B.F. 1988. Muscle weakness among elite power lifters. Med. \& Sci. Sports Exerc. 20 :S 81

Kettunen, J.A., Kujala, U., Sarna, S., Kaprio, J. 2011. Cumulative incidence of shoulder region tendon injuries in male former elite athletes. Int. J. Sports Med. 32(6): 451-4.

Kuhlman, J.R., Iannotti, J.P., Kelly, M.J., Riegler, F.X., Gevaert, M.L., Ergin, T.M. 1992. Isokinetic and isometric measurement of strength of external rotation and abduction of the shoulder. J. Bone Joint Surg. 74(9):132033

Lord, J.P., Aitkens, S.G., McCrory, M.A., Bernauer, E.M. 1992. Isometric and Isokinetic measurement of hamstring and quadriceps strength. Arch. Phys. Med. Rehabil. 73(4): 324-30.

MacDermid, J.C., Ramos, J., Drosdowech, D., Faber, K., Patterson, S. 2004. The impact of rotator cuff pathology on isometric and Isokinetic strength, function, and quality of life. J. Shoulder Elbow Surg. 13(6): 593-598.

Magnusson, S.P., Gleim, G.W., Nicholas, J.A. 1990. Subject variability of shoulder abduction strength testing. Am. J. Sports Med. 18: 349-353. 
Malerba, J.L., Adam, M.L., Harris, B.A., Krebs, D.E. 1993. Reliability of dynamic and isometric testing of shoulder external and internal rotators. J. Orthop. Sports Phys. Ther. 18(4): 543-52.

Marília Dos Santos Andrade, Anna Maria Fleury a , Claudio Andre Barbosia de Lira b , João Paulo Dubas a \& Antonio Carlos da Silva (2010). Profile of Isokinetic eccentric-toconcentric strength ratios of shoulder rotator muscles in elite female team handball players J. Sports Scien., May; 28(7): 743-749

McCabe, R.A., Nicholas, S.J., Montgomery, K.D., Finneran, J.J., McHugh, M.P. 2005. The effect of rotator cuff tear size on shoulder strength and range of motion. J Orthop. Sports Phys. Therap. 35(3): 130-135.

McMaster, W.C., Long, S.C., Caiozzo, V.J. 1992. Shoulder torque changes in the swimming athlete. Am. J. Sports Med., 20: 323-327

Murphy, A.J., Wilson, G.J. 1996. Poor correlations between isometric tests and dynamic performance: relationship to muscle activation. Eur. J. Appl. Physiol. Occup. Physiol. 73(3-4): 353-7.

Nadine, A. Plotnikoff, D. MacIntyre, L. 2002. TestRetest Reliability of Glenohumeral Internal and External. Rotator Strength. Clin. J. Sport Med., 12: 367-372.

Pappas, A.M., Zawaki, R.M., Sullivan, T.J. 1985. Biomechanics of baseball pitching: A preliminary report. Am July-Aug 13(4): 21622.

Pincivero, D.M., Lephart, S.M., Karunakara, R.A. 1997. Reliability and precision of Isokinetic strength and muscular endurance for quadriceps and hamstrings. Int. J. Sports Med., 18: 113-17

Ramsl, M., Swanik, K.A., Swanik. C.B., Straub, S., Maltacola, C. 2004. Shoulder-rotator strength of high school swimmers over the course of a competitive season. Sport Rehabil. 13: 9-18. (C)2004 Human Kinetics Publishers, Inc

Sahaly, R., H. Vandewalle, Driss, T., Monod, H. 2001. Maximal voluntary force and rate of force development in humans importance of instruction. Eur. J. Appl. Physiol. 85(34):345- 350 .

Sapega, A.A., Nicholas, J.A., Sokolow, D., Saranti, A. 1982. The nature of torque "overshoot" in Cybex Isokinetic dynamometry. Med. Sci. Sports and Exer. 14(5): 368-75.

Stickley, C.D. Ronald, K. Hetzler, B. Freemyer, G. Kimura, I.F. 2008. Isokinetic Peak Torque Ratios and Shoulder Injury History in Adolescent Female Volleyball Athletes. J. Athl. Train., 43(6): 571-577

Tyler, T.F., Nahow, R.C., Nicholas, S.J., McHugh, M.P. 2005. Quantifying shoulder rotation weakness in patients with shoulder impingement. J. Shoulder Elbow Surg. 14(6): 570-574.

Wang, H.K., Cochrane, T. 2001. A descriptive epidemiological study of shoulder injury in top level English male volleyball players. Int. J. Sports Med. 22(2): 159-163.

Yildiz, Y., Aydin, T., Sekir, U., Kiralp, M. Z., Hazneci, B., \& Kalyon, T. A. 2006. Shoulder terminal range eccentric antagonist/concentric agonist strength ratios in overhead athletes. Scand. J. of Med. Sci. Sports, 16: 174-180. 